Mary E. Styslinger

\title{
Multigenre-Multigendered Research Papers
}

Mary E. Styslinger asked high school seniors to explore genre and gender in a nontraditional research project. She then "sought to discover more about what students knew and how students' knowing was represented." Her analysis reveals that the multigenre paper can be a powerful form that allows for complexity, questioning, and the development of personal voice.

Suppose no one asked a question, what would be the answer?

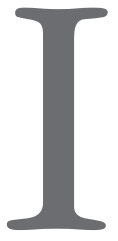

- Gertrude Stein

like to ask questions. I ask them of colleagues, administrators, students and, especially, of myself. I embrace the process of seeking, of not knowing. Questions provide a structure to my days in the classroom. In lieu of moving through a district-mandated textbook chronologically, I organize reading, writing, and learning into focus units. Not so uncommon today, this was fairly groundbreaking in 1990 when the band Aerosmith was making its first comeback.

Frank Serafini defines a focus unit as "a series of literary experiences that revolves around a central theme or focus, such as the works of a particular author, a content topic like geology, or a theme like freedom or immigration" (40). In our English IV class, one familiar work acted as a core text for each unit of study (e.g., Beowulf, The Canterbury Tales, Macbeth, Brave New World). In addition to the canonical work, we explored other topic-related genres including poetry, drama, fiction (short stories, young adult novels), nonfiction (essays, biographies, autobiographies, memoirs, testimonials, diaries, journals, letters, newspapers), nonprint media, and the arts. Over the course of a few weeks, we would read around a common idea bound together by multiple texts. The central topics included the likes of Heroes Among Us (Beowulf), Observations of Everyday Life (The Canterbury Tales), and How Far Would You Go (Macbeth). As a class, we inquired into a particular topic or focus together, with questions providing the fodder for our engagements.
A predictable workshop structure for reading and writing around a focus provided additional classroom order. Reading workshop included read-aloud, whole-class discussion, comprehension lessons, word study, independent reading, reading journals, formal analysis, literary criticism, book clubs, and reader's chair. Writing workshop included craft study, writer's notebooks, genre study, independent writing, writing conferences, peer conferences, student reflection, portfolio assessment, and author's chair.

While this overriding structure allowed me to satisfy district expectations (for more classic literary study) and personal beliefs about how we learn best to read and write (through authentic workshop experiences), I was puzzled as to how to interweave the research paper and these literacy experiences. I did not want to stop teaching the way I was teaching just to satisfy a mandated writing requirement. And I did not like what I saw around me. Every spring in every senior class, the research paper bloomed like crocus. Most teachers waited until March so that they could keep the twelfth I did not want to stop teaching the way I was teaching just to satisfy a mandated writing requirement. And I did not like what I saw around me. Every spring in every senior class, the research paper bloomed like crocus. graders focused on this single task and could wield the threat of missing graduation. In response, I decided to create a more integrated and inquiry-based approach to the traditional research paper. 
It was February, not quite March, in the new millennium. We were finishing our Fate of Love reading and writing around Romeo and Juliet and moving toward a focus on gender. Many questions had arisen from heated discussions of relationships, and this seemed like the perfect time to explore the role gender plays in society. The upcoming unit included the voices of A. R. Ammons, Maya Angelou, India Arie, Gwendolyn Brooks, Lucille Clifton, Rita Dove, Nikki Giovanni, Donald Justice, Doris Lessing, Alice Munro, Marge Piercy, Theodore Roethke, and Virginia Woolf. I hoped that these authors would resonate with students and guide their explorations of gender and its relationship to language, media, body, careers, family, and relationships. Through classroom engagement in personal-response activities such as body traces, debates, and tableaux, we would critically consider the part gender performs in our lives.

\section{The multigenre research paper allows students equal access to voice(s), and its flexible structure permits them to utilize those genres most comfortable and suitable for representing independent ideas.}

But how were students to represent their learning about self and society through writing? An essay seemed too simple. An objective test, absurd. A creative project, trite. The research paper requirement loomed above. How could students transform their consciousness into a written form that others could understand? The answer was obvious. There was not a singular form that could adequately convey what students were thinking and learning. Instead, multiple ways of seeing and saying were needed. I found support and ideas in the work of several composition scholars (Allen; Bishop; Gardner; Macrorie; Rief; Romano; Weathers).

I asked students to write a multigenre research paper that represented their thinking through class readings and conversations about gender. I asked a question: What role does gender play in your life? I expected student responses would come from the events of their daily lives (Graves); thus, the process of research was defined quite broadly and considered as the reflective effort of studying the world and creating ways of sharing what they had learned about it (Eisner). Like Gregory Shafer, I wanted students to embrace research as a personal and organic experience-as a means of exploring their self(ves), their values, and their role(s) in society. Their ways of see- ing and saying would take the form of "crots," a series of self-contained pieces that could appear in multiple forms such as poetry, prose, lists, drama, art, and exposition. They could mix fact with imagery, memory with imagination (Romano), in their efforts to convey thinking and knowing to others.

Multigenre research papers belong in classroom writing workshops. At the secondary level, too much emphasis on product (e.g., five-paragraph essays) and argument (e.g., persuasive rhetorical forms) has left many students feeling silenced. The multigenre research paper allows students equal access to voice(s), and its flexible structure permits them to utilize those genres most comfortable and suitable for representing independent ideas. At the same time, multigenre research papers can provide a rich source of data for teachers curious about their students' development as thinkers.

What did multigenre research papers reveal about students' understandings of gender? And what can we learn about writing from multigenremultigendered research papers? These are the questions that naturally emerged as I, too, engaged in inquiry, immersing myself in the reflexive processes of teaching and researching. To answer these queries, I relied on the information revealed by students' writings. Through close examination, interpretation, and categorization of these classroom artifacts, I engaged in both curricular and methodological inquiry. Concurrently I sought to discover more about what students knew and how students' knowing was represented.

\section{What Multigenre-Multigendered Research Papers Reveal about Gender}

Carol Gilligan suggests that women tend to see the world in terms of connections; interrelationships, friendships, kinships, and memberships lead them to define who they are (In a Different). Awareness of self comes from interaction and association with others. Identity is defined in the context of relationship. While I was familiar with this well-established theory, I was surprised to see such blatant support for these ideas in the writings of female students. The multigenre-multigendered papers written by female students tended to represent gender through their associations with significant others. Overwhelmingly, these authors defined the role gender 
plays in their lives through detailed descriptions of interactions with friends and boyfriends.

In "Language: The Difference between the Genders," Rachel includes a note written to Michelle:

Oh my Gosh!!! I am sooooooo happy for you! So, Josh finally asked you out on a date?! Where are you going? What are you going to wear? Hey, let's go pick out a new outfit tomorrow after school, okay? WOW!!! This is so exciting! You've got to tell me every single thing that happens. Every detail. Oh yeah, how did he ask you? Tell me the exact words - then we can discern precisely what he was thinking at the time. Whoa, I just thought of something. What in the world will you guys talk about!? I know you, you clam up when you are nervous. Well, don't worry: RACHEL to the RESCUE! I will make sure your date is perfect.

Most apparent in this excerpt, other than the obvious use of intensifiers, is the relationship between Rachel and Michelle. Rachel affirms Michelle's happiness, asking questions to demonstrate her interest and offering assistance in perfecting the date. Rachel writes nothing of herself in this note-in this multigenre paper-yet she reveals much about her interpretation of self by not doing so. She has chosen to define her self through others.

Rachel is much like Cameron, whose paper, "What a Girl Wants," includes an excerpt from her diary. In this entry, she describes the beauty and magic of a first kiss. The bonfire and the moon are vividly detailed, along with the tingle that races through her body the minute a boy's lips touch hers, and the coldness that replaces it when he fails to call later that night as promised. Although Cameron reveals more of her personal self and her feelings in this entry than does Rachel, she still writes about her experience in relation to anotherher gendered self is the result of a kiss from that other. When asked to define the role of gender in her life by her English teacher, she includes a rather stereotypical image of herself receiving a kiss from a boy. She is a passive recipient, dependent on the lips of another for a gendered experience.

In contrast to the "care orientation" of females lies the "justice orientation" (Gilligan, "Moral Orientation" 21), often associated with males. Gilligan writes that males tend to frame conflict in terms of individual rights; value detachment, independence, and autonomy; assume separation and the need for an external structure of connection; appeal to rules or reason to resolve conflict; value logic, rationality, and control over the needs of others; and attend to rights and respect. While the multigenre papers written by female students in this class revealed their concern with and for others, these same female students chose to represent males through their writing as less concerned with and for others. Playing with perspective and voice, Felicia writes, "I hate girls. They are always trying to play with us boys. Why can't they leave us guys alone? They wear stinky perfume. They have cooties. Girls are always combing and brushing their hair. They are stupid. They always cry about everything. I hate it when they run up and try to kiss you. Gross. They don't know how to play football, and they don't know how to play war. They just
A multigenre paper is a unique work. The individual who chooses and creates the crots necessary to transform experience from personal to public is challenged to provide a sense of particularity that abstractions cannot render and paragraphs cannot conceal. don't know how to die right." Felicia represents boys as desiring independence and girls as wanting interdependence. Through her multivoiced paper, she portrays males as simply wanting to be left alone.

How, then, did male students seek to define their selves and their gendered counterparts? Male students in this class rejected traditional gendered identities. In a farcical ' 50 s television script, Cade denounces stereotypical gender roles:
(Father opens the door after a hard day at work)
"Hey Honey! Hey Billy! Hey Suzie!"
(Mother and children together)
"Hi Dad!"
"Honey, would you like some biscuits and peas and potatoes and meat loaf?"
"I sure would love some dinner, would you fix our plates, Hun?"
"Sure Dan, what do you think I married you for?"

This same author includes another crot titled "A Hermaphrodite Speaks to the Walls." Gender issues are problematized as this poem's speaker expresses feelings of being "strong," "weak," and "in between."

The male students' understandings of gender reveal an awareness and rejection of gendered societal expectations. At the same time, lending support to the idea that males tend to focus on the self, females are hardly present in the multigenre papers written 
by these young men. Their papers demonstrate the individual's (male) search for identity. It needs to be again mentioned, however, that when females are present, they are described as young women defying gender expectations and limitations. This focus unit of study seems to have had a profound impact on male students in this class as they appear to have abandoned more-traditional gender roles when writing.

\section{What Multigenre-Multigendered Research Papers Reveal about Writing}

It is apparent that these multigenre research papers allow for some interesting insight into student understandings of gender. Inspired by Elliot W. Eisner, I also suggest that these classroom writings offer a sense of particularity, empathy, and complexity not always attainable in more traditional compositional forms or available in more common modes of representing research such as essays.

A multigenre paper is a unique work. The individual who chooses and creates the crots necessary to transform experience from personal to public is challenged to provide a sense of particularity that abstractions cannot render and paragraphs cannot conceal. The choices of creative form empower students with clear and strong voice(s). The voices are there, emanating from the page (Murray). Listen to Nicki, whose mother died less than a year ago, choosing to begin her paper with a definition:

Mother n. (muTH'.er)

1) human with feminine characteristics

2) adult female person who is caring, understanding, knowledgeable, nurturing, and loving syn. my mom

A journal entry follows: "The world stopped for me that day. I remember the events before she told us and perhaps a little after, but the world stopped when my mom said, 'I have cancer."' A newspaper obituary scanned onto the next page records the specifics of a funeral; dates, addresses, times, and names detail the family's loss. And an imaginary dialogue captures the pain of the aftermath:

"Mom, I'm worried about Dad."

"I know you are. Tell me what is bothering you."

"Dad doesn't spend time with us anymore! We never even go out to dinner. And Cory and I are alone on the weekends. He dates a lot and it upsets me because I feel like he has forgotten you."
I cry again as I read this paper, so lost am I in the facts of an encounter with death painfully relayed through multiple genres.

Such feelings of empathy are not uncommon when reading multigenre papers. Seeing and saying through multiple forms encourages greater understanding of lived experience:

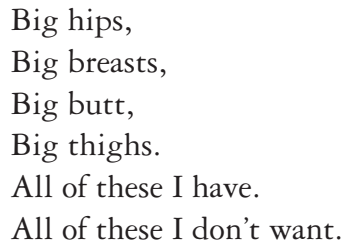

Melissa prompts consideration and compassion through the words of her speaker-self. Empathy is often the result of the sense of particularity provided through multiple genres.

Great complexity can also be conveyed through multigenre papers. When students are no longer limited by the number of paragraphs, citation formats, or singleness of form, students are no longer constrained by singularity of idea. Multiple forms prompt multiple representations of knowing. Rather than a singular demonstration of a truth, students are encouraged to explore varied truths, a task much better suited for fostering critical thinking within this democratic, diverse society. While some students may struggle with the flexible structure and nature of such a paper, this cognitive struggle only enhances and deepens intellectual and emotional growth (Romano). Tanya demonstrates a "thinking through" of the complexities of gender in the following fictional exchange between a preschool teacher and her friend:

Elizabeth: Guess what happened to me at work this week.

\section{Patricia: What?}

Elizabeth: You know how we have the different centers for the kids to play in at school?

\section{Patricia: Centers?}

Elizabeth: You know, art center, block center, dramatic play ... well, really it's like a dress up center, and then there's the reading center. Well, anyway, we have this little boy, La Shawn, who loves to play in the dramatic play center. He puts on the long, blond wig, dresses up in high heels and women's jewelry. He LOVES to dress up. 
Tuesday, he dressed up in ballerina clothes, and his dad comes in.

\section{Patricia: So?}

Elizabeth: So his dad wants me to tell La Shawn that he can't play in the dramatic play center any more. Well, all centers are open to all of the children, and I told his dad that I wouldn't do it.

Patricia: Then what did his daddy do?

Elizabeth: The whole family went home that day and prayed that La Shawn would not be a homosexual. The dad had a meeting with the director of Child Development Center.

Patricia: Tiffany?

Elizabeth: Yes, Tiffany, and he told her that we, the First Holy Lutheran Church Development Center are promoting homosexuality.

Patricia: You're kidding.

Elizabeth: I'm not kidding. Yep, the First Holy Lutheran Church is promoting homosexuality.

With this dialogue, Tanya problematizes the nature and notion of gender, prompting the reader to draw her or his own conclusions.

Multigenre research papers can increase the variety of questions asked in the classroom and in research. Students and teachers who embrace the highly reflexive process of questioning, of seeking, will find the multigenre paper a powerful means for exploration.

\section{Works Cited}

Allen, Camille A. The Multigenre Research Paper: Voice, Passion, and Discovery in Grades 4-6. Portsmouth: Heinemann, 2001.

Bishop, Wendy, ed. Elements of Alternate Style: Essays on Writing and Revision. Portsmouth: Boynton/Cook, 1997.

Eisner, Elliot W. "The Promise and Perils of Alternate Forms of Data Representation." Educational Researcher 26.6 (1997): 4-10.

Gardner, Howard. Frames of Mind: The Theory of Multiple Intelligences. New York: Basic, 1983.

Gilligan, Carol. In a Different Voice: Psychological Theory and Women's Development. Cambridge: Harvard UP, 1982.

. "Moral Orientation and Moral Development." Women and Moral Theory. Ed. Eva Feder Kittay and Diana T. Meyers. Totowa: Rowman, 1987. 19-33.

Graves, Donald H. A Fresh Look at Writing. Portsmouth: Heinemann, 1994.

Macrorie, Ken. The I-Search Paper Rev. ed. Searching Writing. Portsmouth: Boynton/Cook, 1988.

Murray, Donald M. Crafting a Life in Essay, Story, Poem. Portsmouth: Boynton/Cook, 1996.

Rief, Linda. Vision and Voice: Extending the Literacy Spectrum. Portsmouth: Heinemann, 1999.

Romano, Tom. Blending Genre, Altering Style: Writing Multigenre Papers. Portsmouth: Boynton/Cook, 2000.

. Writing with Passion: Life Stories, Multiple Genres. Portsmouth: Boynton/Cook, 1995.

Serafini, Frank. The Reading Workshop: Creating Space for Readers. Portsmouth: Heinemann, 2001.

Shafer, Gregory. "Re-envisioning Research." English Journal 89.1 (1999): 45-50.

Weathers, Winston. An Alternate Style: Options in Composition. Rochelle Park: Hayden, 1980.

Mary E. Styslinger is assistant professor of English education at the University of South Carolina, director of the Midlands Writing Project, and a teaching team member with the South Carolina Reading Initiative-High School. Her research and writing interests include the intersection of gender and language/literacy education. email: mstyslin@gwm.sc.edu. 